\title{
Catalogue of the Bees (Hymenoptera, Apoidea) in the Neotropical Region
}

Not only taxonomists but all biologists working on Neotropical bees will greatly welcome this authoritatively prepared catalogue published in 2007. Since Dalla Torre's (1896) worldwide catalogue, no other comprehensive work of the Neotropical bee fauna has been produced. The major backbone for the catalogue was the extensive database compiled by Padre Jesus Santiago Moure during his long and exemplary academic career. It is complemented by similarly extensive databases prepared and provided by several contributors, including the organizers of the publication, Danunzia Urban and Gabriel Augusto Rodrigues de Melo at the Universidade Federal de Paraná, Curitiba, and the curators of the stingless bee collection at the Universidade de São Paulo, João Maria Franco de Camargo and Silvia Regina de Menezes Pedro. The catalogue lists 6811 species-group names, including a total of 5016 names representing valid species, 5000 extant and 16 fossil taxa. Being the most intensively studied group of bees, it comes to no surprise that one third of the catalogue is dedicated to stingless bees. With this wealth of taxonomic and bibliographic infomation (it is an inventory of the taxonomic literature up to 2007 and lists all further publications on particular species at least up to 2004), the catalogue, which was prepared by the contributors in a five years joint effort, will be a major resource for everyone working directly with systematics, taxonomy and biology of bees, as well as conservation, habitat restoration, plant reproductive biology, and pollination.

More information, including on how to obtain a copy of the catalogue, is available through the site http://zoo.bio.ufpr.br/hymenoptera/index.htm. Having received financial support from several Brazilian funding agencies, the catalogue can be directly ordered from the Sociedade Brasileira de Entomologia, at a symbolic prize that is set to only cover the mailing costs, because, after all it is an oeuvre weighing $3 \mathrm{~kg}$. Furthermore, an electronic version of the catalogue is currently under preparation (http://moure.cria.org.br/project), with some groups already being searchable online.

The Editors of Apidologie congratulate the organizers and contributors for the conclusion of this major resource to bee research. 